\title{
Intracranial Stents Past, Present and the Future Trend: Stents Made with Nano-particle or Nanocomposite Biomaterials
}

Junjie Zhao ${ }^{a}$, Deepak Kalaskara, Yasmin Farhatnia ${ }^{a}$, Xiaoxin Bai ${ }^{\text {b }}$, Peter E. Bulter ${ }^{a, b}$, Alexander M. Seifaliana,c *

${ }^{a} U C L$ Centre for Nanotechnology and Regenerative Medicine, Division of Surgery \& Interventional Science, University College London, London, United Kingdom

${ }^{\mathrm{b}}$ Guangdong Provincial Hospital of TCM, Guangzhou, P. R. China

${ }^{\mathrm{c}}$ Royal Free London NHS Foundation Trust Hospital, London, United Kingdom

Running Title: Intracranial Stents Past and Future: a review

*Corresponding author:

Professor Alexander M. Seifalian

Professor of Nanotechnology \& Regenerative Medicine and Head of Department

UCL Centre for Nanotechnology and Regenerative Medicine

Division of Surgery \& Interventional Science

University College London, London, United Kingdom.

Tel.: +442078302901.

E-mail: a.seifalian@ucl.ac.uk 


\begin{abstract}
Stroke or cerebral vascular accidents are among the leading causes of death in the world. With the availability of Digital Subtraction Angiography, transluminal angioplasty has become feasible in many situations and the role of intracranial stents is becoming ever more important in the management of cerebral vascular diseases. In current review, we outline the chronological development of various stents namely; balloon expandable stent, selfexpandable open cell stent, self-expandable close cell stent and the flow diverting stent. Further we discuss their advantages and limitations in terms of stent migration, thromboemboli, damage to vessels during procedure, in-stent stenosis and hyper-perfusion damage. We also discuss the importance of in-situ endothelialization, controlled expandability and hemodynamic manipulation in stent design. Further, we summarized the role and need for further development in the areas of bio-compatible materials, endothelial progenitor cell capture technique, bio-functionalized-magnetic-nano-particles and nanotechnology which are significant in intracranial stent development.
\end{abstract}

Keywords: nanocomposite, POSS-nanocomposite, bio-functionalized material, endothelial progenitor cell capturing, hyper-perfusion damage, in-situ endothelialization, in-stent stenosis, intracranial stent, nanotechnology, 


\section{Introduction:}

Strokes or Cerebral vascular accidents (CVAs) are among the leading causes of mortality and morbidity in the world, second only to ischemic heart diseases. While the mortality of ischemic heart disease has shown a tendency of steady decline in the UK over the last decade, both the prevalence and mortality of cerebro-vascular disease have continued to climb as a result of the increase in the prevalence of risk factors in the community and the slow progress in disease management. According to the World Health Organization (WHO) report in 2004 [1], mortality of cerebro-vascular disease in the UK alone is 45.6 in every 100,000 people, accounting for $8.3 \%$ and $12.7 \%$ of overall mortality in males and females respectively. Compared to the figures in 2002 , the overall mortality and the distribution of death due to CVA in both genders had increased.

CVAs can be broadly classified into two major subtypes: ischemic and hemorrhagic. About $87 \%$ of strokes are ischemic while the remaining are hemorrhagic. In an ischemic stroke, blood supply to certain area of brain is interrupted. A hemorrhage attack is the result of a ruptured blood vessel, usually due to hypertension or abnormalities in vascular structures such as intracranial aneurysms, arteriovenous malformation, etc. With the advancement in Digital Substraction Angiography (DSA), interventional treatment strategies such as angioplasty with/without intracranial stent, transluminal thrombectomy and coil embolization with/without stent assistance have become feasible. It is not difficult to see the role of intracranial stents are becoming more prominent in the future management of neuro-vascular disease. A marketing report by New Meditech described the average growth rate in the global market for intracranial stents as being $45 \%$ over the past five years, it also forecasted the global market of intracranial stents will be close to $\$ 0.5$ billion by 2015 [2]. 


\section{The development of Intracranial Stent}

Precutaneous transluminal angioplasty was first introduced for the treatment of intracranial stenosis more than thirty years ago [3], since then its role has been firmly established. It took off after the invention of Guglielmi detachable coils in the 1990s. Upon the development of intracranial stent itself, there have been roughly four generations of intracranial stent designs, namely: the balloon expandable stent, the open cell self-expandable stent, the close cell selfexpandable stent and the flow diverting stent. And besides the conventional Bare Metal Stents (BMS), intracranial covered stents are also at the point of emerging. Here in the following, we shall discuss in detail of each of these four generation of stents and their representing products. (Figure 1)

\subsection{First Generation of Intracranial Stent - Balloon Expandable Stent (BES)}

In the early stage of intracranial stent development, due to the absence of appropriate intracranial stent designs, balloon expandable coronary stents (Figure 1A) were used in intracranial transluminal angioplasties for the purpose of crushing plaques and dilating vessel lumens. Such procedures were deemed to have high risks of distal thrombembolism and perforator occlusion as a result of plaque fragments being produced during procedure. Apart from angioplasties, the first reported use of BES in stent-assisted coil embolisation for intracranial aneurysms was in 1997, by Higashida et al. However, subsequent use of BES in the treatment of intracranial aneurysms was met with a high deployment failure rate (15\%, Lylyk et al), high procedural related hemorrhage rate (7\%, Han et al) and significantly delayed instent stenosis rate (4\%, Linzino et al), with the long term neurological morbidity and overall mortality being $8 \%$ and $5 \%$ respectively according a cross series study. 


\subsection{Second Generation of Intracranial Stent - Self Expandable Open Cell Stent}

\section{(OCS)}

\subsubsection{Neuroform stent}

In 2002, the Food and Drug Administration (FDA) approved the first stent designed specifically for intracranial application, the Neuroform stent (Boston Scientific Neurovascular Fermont, California, USA. Figure 1B). It is a stent with 6-8 linked radiolucent cells comprised of a nickel-titanium alloy (national). In a cross study of 19 series related to Neuroform stent, the overall deployment failure rate was $7 \%$, stent migration was approximately $2 \%$, and the permanent neurological morbidity and mortality was $4 \%$ and $2 \%$ respectively [4]. Lessne et al reported in their series that symptomatic thromoembolic event rate was $8 \%$, while postprocedural intracranial hemorrhage was observed in $3 \%$ of patients. However the cause of these hemorrhages could be the rupture of residual aneurysms, instead of procedure-related trauma [5].The second generation of Neuroform stents, Neuroform 2, were released in 2003, with the additional feature of a hydrophilic braided micro-catheter. This has cut the deployment failure rate further to $4-5 \%$ [6]. Nevertheless its inability to navigate and deploy was still constantly reported in clinical case reports.

The third generation, Neuroform 3, was designed to have an extra connector between the adjacent segments so as to decrease the area of open cells and increase the strength of the stent. It has almost the same wall apposition but weaker radial force, which improves its navigational performance. It also incorporates a braided stabilized catheter which can reduce fraction during deployment, minimizing vessel trauma. 


\subsubsection{Wingspan stent}

Another OCS available on the market is the Wingspan stent (Striler/Boston Scientific SMART Fermont, California, USA. Figure 1C). It is made of nitinol, and approved by the FDA in 2005. The clinical properties of the Wingspan stent were well documented in the Stenting and Aggressive Medical Management for Preventing Recurrent Stroke in Intracranial Stenosis (SAMMPRIS) trial. Fiorella et al reported in an analytical study of the SAMMPRIS trial: successful deployment in $98 \%$ of all cases, 0 stent migration observed, and mortality or ipsilateral stroke in 30-day is $4 \%$, follow-up mortality and recurrence of stoke is $1 \%$ and $3 \%$ respectively [7]. Another study on Wingspan stent in treating intracranial arteriosclerosis by Siddiq et al reported a delayed in-stent stenosis rate of $0.96 \%$ and a post-procedural hemorrhage rate of $6.25 \%$, which is most likely due to hyper-perfusion damage. Other results of this study resemble the SAMMPRIS trial [8].

The result from the SAMMPRIS trial suggested that, due to high risk of peri-procedure complication rate, stenting with Wingspan stent has no superiority over aggressive medical treatment in intracranial arteriosclerosis. However, there are several small sample studies following the SAMMPRIS trial with more strict inclusion criteria point to better treatment outcomes and lower complication rate [9]. All these suggest a new trial with more strict enrolling criteria should be considered, and this proposal is gaining wider supports after the follow-up result for aggressive medicine treatment group in the SAMMPRIS trial is revealed. That result showed high recurrent stroke rate in the second year of aggressive medicine treatment, which might imply in high risk patients, the protective effect of aggressive medicine treatment in preventing stroke decline significantly after the first year. 


\subsection{Third Generation of intracranial stent - Self Expandable Close Cell Stent (CCS)}

\subsubsection{Enterprise Stent}

Enterprise stent (Cordis, Florida, USA. Figure 1D) was approved by the FDA in 2007. It has a close cell designed stent made of nitinol. Inherited the elasticity nature of its predecessor, the close cell structure gives it a much stronger supporting strength and radial force. Furthermore, it has the ability to be recaptured and repositioned after deployment. It was reported that the Enterprise stent can be recaptured after up to $70 \%$ of deployment. This "semideployment" technique gives it an enormous advantage in device delivery and deployment. However, the close cell design has also lead to an increase in stiffness and decrease in plasticity, and the stent-vessel wall interface in vessels with high degree of curvature is not as good as the OCS. There had been case reports on vascular perforation by Enterprise stent radiopaque maker during a stent-assisting coiling procedure [10], and stent entanglement occurred in overlapping two Enterprise stent (Figure 2) [11], this might lead to disastrous result. Apart from those, there was also one rare case report of possible nickel allergy after Enterprise stent placement [12].

In a cross study of 11 series, the deployment failure rate of the Enterprise stent was only $1 \%$, while delayed in-stent stenosis rate was $3 \%$ and peri-procedural hemorrhage rate was $2 \%$ [13]. Another series by Mocco et al on the Enterprise stent in treating intracranial aneurysms showed a $6 \%$ of temporary morbidity rate, and the permanent neurological morbidity and mortality were $2 \%$ and $1 \%$ respectively [14]. 


\subsubsection{LEO Stent}

The LEO Stent (Balt, Montmoerncy, France. Figure 1E) is a stent made of nitinol. It is currently not available in North America due to its poor treatment outcomes in clinical trials. LEO stent was designed with a small close cell structure which gave it even greater radial force and elasticity. It can be re-sheathed and repositioned at up to $90 \%$ of deployment. The small cell design gives it a certain level of hemodynamic property, but this might also be the cause of its high thromboemolic incidence for it interrupted the blood flow to the perforators located on the path of its coverage. In a cross study of 3 series covering 64 cases of intracranial aneurysms treated with LEO stent, deployment failure was observed in 3 cases (5\%), stent migration in 1 case (2\%), $14 \%$ of post-procedure thromboemolic event, and the morbidity and mortality were $4 \%$ and $3 \%$ respectively [15]. Despite its poor clinical outcome, it is undeniable that its hemodynamic quality has inspired the emerging of the Flow Diverting Stent.

\subsubsection{Solitaire Stent}

The Solitaire Stent (ev3, Irvine, California, USA. Figure 1F) is the first fully retrievable stent. It is designed with large cell structure, and is made up of nitinol in a honey comb pattern. It gives the device additional flexibility and elasticity, making it easier for delivery and deployment. It is designed to be detached electrolytically from a push wire. It showed low thrombogenicity in clinical trials. It is not approved to be used for stent-assisting coiling in the North America. However, it is now most widely used in clinic for mechanical thrombectomy [16].

Solitaire Stent showed no cases in deployment failure, stent migration and in-stent stenosis in treating acute intracranial artery occlusion. However it did show 6\% peri-procedural 
hemorrhage events and the reported mortality is $17.4-22.2 \%[17,18]$. Due to the limitation in its usage, the clinical data is not as good as the other intracranial stents. Yet, when comparing with other approaches like venous thrombolysis, arterial thrombolysis and the Merci Clot Retriever System in treatment of acute intracranial arterial occlusion, the data from Solitaire Stent is already significantly better.

Despite all the adverse effects of Solitaire, there was one rare case of stent breakage during treatment procedure observed in a Korean study [19].

\subsection{The Forth Generation of intracranial stent - Flow Diverting Stent (FDS)}

\subsubsection{Silk Flow Diverter (SFD)}

The Silk Flow Diverter (Balt Extrusion, Montmorency, France. Figure 1G) is a closed cell stent; it is composed of 48 braided nitinol strands and $35 \mu \mathrm{m}$ platinum microfilaments. It can be retrieved after up to $90 \%$ of deployment, it is flexible but has a relatively lower level of radial force than other close cell stents. As a result, it can reduce wall shear stress while decreasing the blood flow volume to its covered structures. Such properties are useful in treating intracranial aneurysms. It can stop blood flowing into the aneurismal lumen inducing hemostasis and thrombosis inside. However, low radial force has contributed in its higher rate of stent migration after deployment. The results of SFD related treatment outcomes in a cross study of 10 series reported deployment failure rate to be $3 \%$, stent migration in less than 1 percent of overall cases, embolic events and hemorrhage events are observed in $7 \%$ and $3 \%$ separately, in-stent stenosis rate is $10 \%$ and neurological morbidity and mortality are $6 \%$ and $4 \%$ respectively [20-22].

As SFD started to be used in treating intracranial aneurysms, we noticed a kind of new complication called Delayed Aneurysm Rupture (DAR), which was later turned out to be a 
common post-procedural complication in all FDS. In the cross study on SFD mentioned above, there are 13 cases of delayed hemorrhage occurred in follow-up, two of which had reports of completely thrombosed on the observed aneurysms in a follow-up prior to the incident. These suggested they were confirmed cases of DAR, while the rest of the cases cannot be differentiated from hemorrhage due to rupture of the residual aneurysms or DAR, and so the overall DAR rate in the study cannot be determined.

\subsubsection{Pipeline Embolisation Device (PED)}

The Pipeline Embolisation Device (PED, ev3, Irvine, California, USA. Figure 1H) is a FDS approved by the FDA in 2011. It is a cylinder composed of 48 woven cobalt and platinum (3:1) alloy microfilaments. It is a close cell design and the woven structure gives it an even greater radial force than SFD. It can be retrieved after total deployment. In clinical practices, the PED showed fewer complications than SFD. The tight woven mesh structure has cause significant decrease in the volume of blood flowing through its wall. A research by Shobayashi et al on the intra-aneurismal hemodynamic alternations confirmed that the PED can significantly reduce both the volume and velocity of intra-aneurismal blood flow [23].

The results from a cross study of 11 series of PED in treating intracranial aneurysms showed the deployment failure was observed in $2 \%$ of cases, embolic events and hemorrhage events rates were $3 \%$ and $4 \%$ respectively, in-stent stenosis rate was $7 \%$ and neurological morbidity and mortality were $2 \%$ and $3 \%$ [24-26]. Also, for the same reason as the study in SFD, the DAR rate cannot be determined in this study.

\subsection{Willis Covered Stent (WCS)}

The Willis Covered Stent (MicroPort Medical Company, Shanghai, China. Figure 1I) is designed as a balloon expandable open cell stent, the bare metal stent is made of a strand of 
cobalt chromium alloy $(\mathrm{CoCr})$ wire with the diameter of $0.06 \mathrm{~mm}$. Outside the bare metal stent is a layer of expandable polytetrafluoroethylene (ePTFE) membrane with a thickness of $30-50 \mu \mathrm{m}$, the membrane and the stent are glued together with a organic agglomerate, in the middle is a balloon catheter. It is not been approved in North America and Europe. There are only few on-going clinical trials of WCS in China, one by Xiao-Biao Lai et al showed the deploy failure rate is $1.9 \%$, both of the embolic events and hemorrhage events rate is $1.9 \%$, delayed in-stent stenosis rate is $11.3 \%$ and neurological morbidity and mortality are $13.2 \%$ and $1.9 \%$ respectively [27]. Summary of characteristics and clinical studies of all the intracranial stents discussed above is summarized in Table 1 and 2 respectively.

\section{Discussion - The Future trend in intracranial stent development}

To review the entire process of the development of intracranial stent itself, there had been three major evolutions in the designs. The first evolution is from balloon expandable to selfexpandable. The limitations of BES are mostly due to its rigid nature as opposed to the high degree of curve and low level of elasticity of intracranial vessels. Also, the balloon's expandable nature has also proven to have caused damage to Endothelial Cells (ECs), resulting in a high rate of undesirable complications such as vessel trauma, perforation, poor wall apposition and delay in-stent re-stenosis. The greatest modification made to overcome the shortages of BES is the self-expandable design. It makes the stent deploying process more smooth and gentle, to protect the parent vessel from trauma. It can also avoid plaques on site being meshed into small emboli by the crushing force from the expanding process. The design of self-expanding nature has been a success in reducing the incidence of deployment failure, parental artery dissertation and vessel perforation. The second major modification is from open cell design to close cell design. Although the open cell design confers a high degree of 
elasticity and plasticity, which improves wall apposition and lowers the risk of vessel spasm in the cases of plain straight vessels. However, in the cases of high degree curve vessels, the open cell nature also created extremely undesirable stent-vessel wall interface. For example, in the case of wide neck aneurysms on a curvy parent artery, the mismatching of the stent body and vessel wall can result in the out stretching of the stent structure, which could poke against the vessel wall and causing the rupture of aneurysms (see Figure 3) [28]. Also, the unretrievable nature of OCSs also presented challenges to the operators in clinical practices. The third is the hemodynamic features are being explored and used on stent designs. For example, lots of hemodynamic researches are being conducted on the FDS, such as jet flows, in-flow volume, in-flow velocity and even the pressure alternation inside the aneurysm. Research by Shobayashi Y et al. revealed that although using PED in treating intracranial aneurysms could reduce both the volume and velocity of blood flowing into the aneurismal lumen, the intraaneurismal pressure did not decrease significantly. It is believed to be one of the mechanisms of DAR [23].

Despite the designs of intracranial stents evolving greatly over time, there are still many well defined problems with the current available intracranial stents: 1) stent displacement and migration, 2) thrombus formation, 3) vessel trauma, and 4) in-stent restenosis (ISR). As there have been great advancements in the design of cardiovascular stents in recent years, many could be followed as examples in the design of intracranial stents [29]. Such as: Drug Eluting Stents armed with functionalized nanoparticles for targeted drug delivery [30], or with the design of layer-by-layer self-assembly techniques to achieve controlled release of medicine from polymers $[31,32]$ have already been developed and currently being put into clinical trials. Besides novel designs, stents with a biologically-friendly coating as [33], and covered stents are also being explored and developed. There are two major types of covered stents, they are covered with either natural or synthetic materials. Natural materials used as covers 
are decellularized animal tissues. The Pericardium Covered Stent (PCS) (ITGI Medical Ltd. Israel) is one such example. It is designed to have two very thin decellularized horse pericardium tissues covering a BMS. So far, there are only scatted cases reports on the PCS, but not yet any clinical studies or trials results be published on it. Although no obvious undesirable effects were reported with using PCS at the moment, there still are concerns on biocompatibility issues. Some suggest that due to the xenogenic nature of such material, it is inevitable that it would trigger unwanted immune reaction, and results in acute or chronic inflammation, leading to the possibility of delay in-stent restenosis in the future. There are also debates on the risk of zoonosis from using xenogenic tissue in humans. As for stents covered with synthetic materials, PTFE covered stents are most common in the market, like the WCSs mentioned above. However, it is proven that PTFE as a biomaterial in small diameter bypass grafts is highly thrombogenic. It causes high risks of thromboembolic complications after stent placement, and often requires a lifetime prescription of dual antiplatelet therapy.

As Nanocomposite Biomaterials are getting more and more attention for their superiority in mechanical properties, durability, biocompatibility and especially the possibility of accomplishing more complex surface modifications than conventional biomaterials, the designs of Gene-eluting stents [34] and nitric oxide incorporating implanting device [35] have become viable. These are all considerable examples to be followed in designing the new generation of intracranial stents.

\subsection{Nanotechnology in designs of FDS.}

In order to solve the complication of DAR, it requires a FDS that can reduce intra-aneurismal pressure. This goal can be achieve via a nanotechnology design that promotes faster intraaneurismal thrombosis. A recent study showed that by combining a utilized material of micro- 
patterned Thin Film Nitinol (TFN) and the technology of hyperlastic fabrication can lead to a design called hpyerlastic-TFN (HF-TFN). It was found that this bio-functionalized material not only processes a desirable degree of flexibility, but also facilitates in-situ microthrombosis when used as a scaffold for blood produce deposition. This finding could be adopted in developing a FDS [36]. In vitro tests using a whole blood circulating model demonstrated formation of a fibrinous network which increases the device's flow limiting capacity. The associated in vivo tests in swine wide neck aneurysm models showed rapid intraprocedural aneurysm occlusion (Figure 4, 5).

\subsection{Magnetic Mediated Nano-Particle Technology}

Hyper-perfusion damage is one of the commonly observed hemorrhage complications from stenting in ischemic cerebral vascular diseases. It is caused by a sudden increase in blood flow to an under-perfuse region of the brain, leading to brain tissue edema and secondary hemorrhage (the risk of intracranial hemorrhage in stent angioplasties is $1.2 \%$ ), both of which can be fatal [37]. The risk raise as the degree of stenosis increases. One recently published paper suggested using magnetic mediated nano-particle technology can achieve controlled micro-movement via applying a shifting magnetic field on bio-functionalized micro-discs [38]. Theoretically, by incorporating these nano-particles into the stent, we can control its expandability via careful manipulation of the extrinsic magnetic field. And by this controlled expandable technology, it should able to eliminate the risk of hyper-perfusion damage.

\subsection{In situ endothelialization}

Despite the improvements made in generations of intracranial stents, both the in-stent and delay in-stent stenosis rates have not shown a significant decline over the years. This may be related to the low bio-compatibility of the stents, the possible EC damage sustained during the 
procedure and poor interfacing between the material surface and cells added on the negative effects. Theoretically, rapid endothelialization of the luminal surfaces of stents is a way of increasaing implant patency and preventing in-stent stenosis by inhibiting both thrombosis and intimal hyperplasia [39]. Recent studies focus on the immobilization of endothelial progenitor cell (EPC) specific antibodies for circulating EPC capturing [40]. Many in vitro and in vivo studies have already successfully induced EPC incorporation onto target sites, and the immobilized EPCs have been observed to be differentiated and proliferated into an EC monolayer [41].

\subsection{Polyhedral Oligomeric Silsesquioxane Polycaprolactone-urea Urethane (POSS- PCU)}

Our lab in the Center of Nanotechnology and Regenerative Medicine, UCL Division of Surgery and Interventional Science, has developed and patented a non-biodegradable nanocomposite polymer for surgical implants - POSS-PCU. Many previous studies have proven that POSS-PCU is an anti-thrombogenic [42], biocompatible [43] and non-toxic [44, 45] biomaterial. It does not cause inflammatory reactions in the surrounding host tissue [4649]. Experiments in cardiac implants also prove that POSS-PCU has a fine quality of calcification resistance (Alobaid et al., 2006; Motwani et al., 2011). POSS-PCU has already been used first-in-human studies as a bypass graft [50], lacrimal duct [51] and the world's first synthetic trachea $[52,53]$.

Since it is well documented that POSS-PCU have such special qualities, it has great potential for cardio- and neurovascular applications. We have already been developing covered stents for treating cardiovascular diseases by using the metal surface treatment technique to induce a POSS-PCU covering onto BMSs, and we are currently incorporating EPC-specific antibodies onto this biomaterial for cell capturing so as to promote in situ endothelialization. 
We will soon be carrying out pre-clinical in vivo studies on them. It is hoped that we will also develop an intracranial covered stent using this biofunctionalized material and similar surface modification technique.

\section{Conclusion}

Comparing with the development of coronary stent, the current position of intracranial stent is still in its infancy. In view of the progress, it is logical to foresee the next generation of intracranial stent being a type of coated or covered stents. With the advancement in biomaterial and nano-technology, newer designs for intracranial stent with optimum performance can be realised. It is our conclusion that EPC capture technique, biofunctionalized material and nano-structures shall all play important roles in the future generation of intracranial stents. With an intracranial stent with the properties of promoting in situ endothelialization, control expandability and hemodynamic manipulation, hopefully the trends of increasing morbidity and mortality due to CVA can finally be reversed.

\section{Disclosures/Conflict of Interest:}

The authors of this review declare none. 


\section{List of Abbreviations:}

BES Balloon Expandable Stent

BMS Bare Metal Stent

CCS Self Expandable Close Cell Stent

CVA Cerebral vascular accident

DAR Delayed Aneurysm Rupture

DSA Digital Substraction Angiography

EC Endothelial Cell

EPC endothelial progenitor cell

HF-TFN hpyerlastic - Thin Film Nitinol

PCS Pericardium Covered Stent

ePTFE expandable polytetrafluoroethylene

FDA Food and Drug Administration

FDS Flow Diverting Stent

OCS Self Expandable Open Cell Stent

PED Pipeline Embolisation Device

POSS-PCU Polyhedral Oligomeric Silsesquioxane Polycaprolactone-urea Urethane

PTFE polytetrafluoroethylene

SAMMPRIS Preventing Recurrent Stroke in Intracranial Stenosis

SFD Silk Flow Diverter

TFN Thin Film Nitinol

WCS Willis Covered Stent

WHO World Health Organization 


\section{Captions:}

Figure 1: The representing products of Intracranial stents: A: the bare metal part of the balloon-expandable intracoronary stent developed by Palmaz and Schatz, absence of the balloon catheter in the middle; B: the Neuroform stent; C: the Wingspan stent, with a balloon catheter inside; D: the LEO stent; E: the Enterprise stent; F: the Solitaire stent; G: the Silk Flow Diverter; H: the Pipeline Embolisation Device; I: the Willis covered stent. Reprinted from online resources with permissions.

Figure 2: CT scan showing A. occurrence of entanglement by overlapping two Enterprise stents: A1 and A2 in sagittal and axial section (left) and the appearance schematic form (right). A3 showed wire passage into and out of the incomplete stent apposition (ISA) isolated lumen (left), followed by advancement of the delivery microcatheter of stent No 2 (middle) and final relative stent positions (right), B. Un-subtracted angiogram showed a radiopaque maker of stent out of ICA (arrowhead). Reprinted from Robert S Heller, et al. with permission from BMJ Publishing. Copyright 2013, Society of NeuroInterventional Surgery.

Figure 3: The interface between the vessel wall and an OCS on a curvy parent artery with a wide neck aneurysm: This diagram show three different kind of stents in the inner curvature of different vessels (A1: vessel harbor an wide neck aneurysm with important branch vessel, A2: vessel harbor an wide neck aneurysm without side branches, A3: vessel harbor an narrow neck aneurysm), the red segment of the stent suggest an undesirable stent-vessel wall interface, and the black arrow head show the stent structure protruding in the parent vessel. The two series of pictures on the left are two different CCSs $(\mathrm{C} 1, \mathrm{C} 2)$, the one on the right is the OCS (C3). Reprinted from S. DeBock, et al with permission from Elsevier Publishing. Copyright 2013, European Society of Biomechanics.

Figure 4: The in vitro testing result of HE-TFN: Scanning Electron Microscopy (SEM) images of the $300 \mu \mathrm{m}$ device at low and high magnification after 1, 2.5, and $5 \mathrm{~min}$ in the whole 
blood circulation model. The HE-TFN plays the role as a scaffold for thrombus deposition, it traps fibrin, platelets, and RBCs as the whole blood flows through. Furthermore, over time, the pores of HE-TEN covered in thrombus increased markedly, and they were almost completely obstructed at the point of 5 min. Reprinted from C. P. Kealey, et al. with permission from John Wiley \& Sons Publishing. Copyright 2013, John Wiley \& Sons, Inc.

Figure 5: The in vivo testing result of HE-TFN: The Gross examination immediately and 42 days after the HE-TFN covered stents implantation show the anurysmal lumen is completely thrombosed while the lumen of the patent artery remains clean and patent (A, B). Thrombus formation can be seen in the abluminal surface of the HE-TFN covered stent, such change in structure prevent thrombus from extending into the parent artery $(C, D)$. In the harvest of the HE-TFN covering stent in 42 days, aneurysm was surrounded by inflammatory adipose tissue and its size was significantly reduced. Reprinted from C. P. Kealey, et al. with permission from John Wiley \& Sons Publishing. Copyright 2013, John Wiley \& Sons, Inc. 
Figure 1



Figure 2

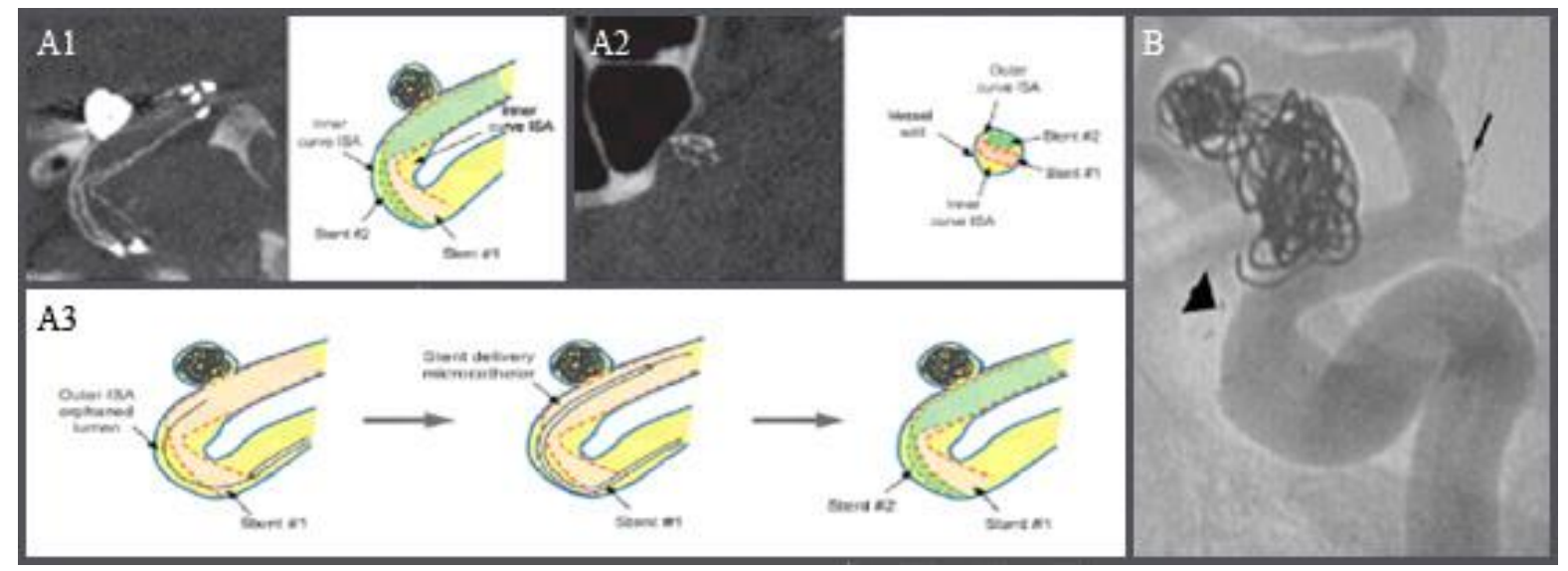


Figure 3

\section{C1}

C2

N1


Figure 4
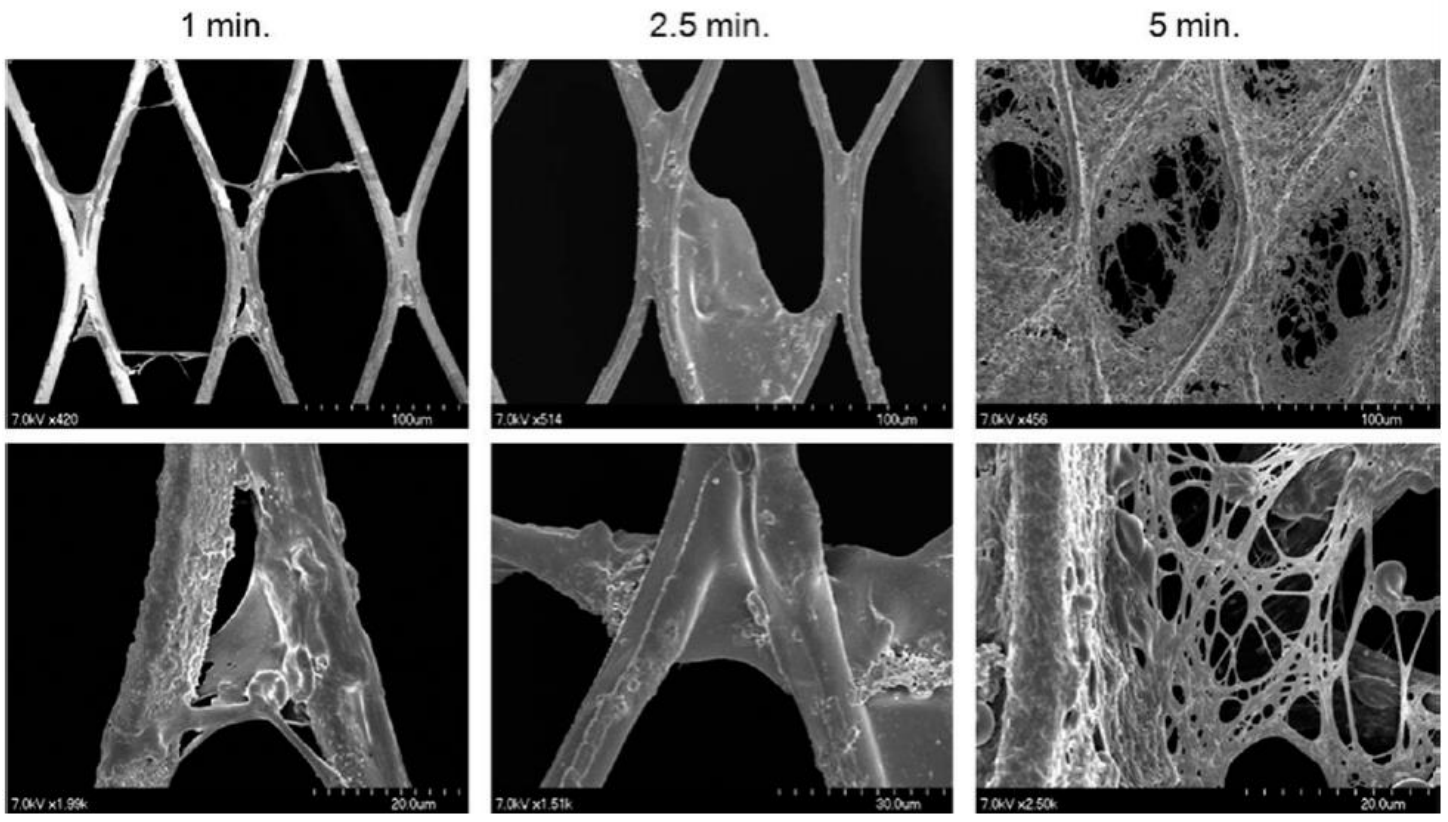
Figure 5




Table 1: The summary of all the currently available intracranial stent.

\begin{tabular}{|c|c|c|c|c|c|c|}
\hline & Neuroform & Wingspan & Enterprise & LEO & Solitaire & SILK \\
\hline $\begin{array}{l}\text { Date Approved by } \\
\text { FDA }\end{array}$ & 2002 & 2005 & 2007 & - & - & - \\
\hline $\begin{array}{l}\text { Composition and } \\
\text { Design }\end{array}$ & $\begin{array}{l}\text { a stent with 6- } \\
8 \text { linked } \\
\text { rdiolucent cells } \\
\text { comprised of } \\
\text { nitinol }\end{array}$ & $\begin{array}{l}\text { self-expanding } \\
\text { stent made of } \\
\text { nitinol }\end{array}$ & $\begin{array}{l}\text { Made of nitnol cells, } \\
\text { flared ends }\end{array}$ & $\begin{array}{l}\text { Made of } \\
\text { nitonl, } \\
\text { braided }\end{array}$ & $\begin{array}{l}\text { made up of } \\
\text { nitinol in a } \\
\text { honey comb } \\
\text { pattern }\end{array}$ & $\begin{array}{l}\text { composed of } 48 \\
\text { braided nitinol } \\
\text { strands and } 35 \mu \mathrm{m} \\
\text { platinum } \\
\text { microfilaments }\end{array}$ \\
\hline Cell Design & Open-Cell & Open-Cell & Close-Cell & Close-Cell & Close-Cell & Close-Cell \\
\hline radiopaque Markers & $\begin{array}{l}\text { Both ends, } \\
\text { each with } 4 \\
\text { radiopaque } \\
\text { markers }\end{array}$ & $\begin{array}{l}\text { Both ends, } \\
\text { each with } 4 \\
\text { radiopaque } \\
\text { markers }\end{array}$ & $\begin{array}{l}\text { Both ends, each with } \\
4 \text { radiopaque } \\
\text { markers, and } 1 \text { with } \\
\text { deliver wire }\end{array}$ & $\begin{array}{l}\text { On its body, } \\
2 \text { wires. }\end{array}$ & $\begin{array}{l}3 \text { distal } \\
\text { markers }\end{array}$ & - \\
\hline Surface coverage & $6.5-9.5 \%$ & - & $10 \%$ & - & $5-7 \%$ & $35 \%$ \\
\hline Retrievability (\%) & No & No & $70 \%$ & $90 \%$ & $100 \%$ & $90 \%$ \\
\hline Radial Force & Median & Median & Median & Lowest & Highest & - \\
\hline $\begin{array}{l}\text { Stiffness when } \\
\text { bending }\end{array}$ & Lowest & Low & Highest & Median & Median & - \\
\hline Cell Size & Median & Median & Median & Smallest & Largest & - \\
\hline
\end{tabular}


Table 2. The summary of adverse-effect rate of specific intracranial stent from selected study series.

\begin{tabular}{|c|c|c|c|c|c|c|}
\hline Stent & $\begin{array}{l}\text { Overall } \\
\text { population }\end{array}$ & $\begin{array}{l}\text { Deployment Failure } \\
\text { Rate (\%) }\end{array}$ & $\begin{array}{l}\text { Stent Migration } \\
\text { Rate }\end{array}$ & $\begin{array}{l}\text { In-stent stenosis } \\
\text { Rate (\%) }\end{array}$ & $\begin{array}{l}\text { Thromboemboli } \\
\text { Event Rate (\%) }\end{array}$ & $\begin{array}{l}\text { Intracranial } \\
\text { hemorrhage Event } \\
\text { Rate (\%) }\end{array}$ \\
\hline Neuroform & 1408 & $\begin{array}{l}7 \text { (4-5 in Neuroform } \\
2)\end{array}$ & 2 & 4 & 8 & 3 \\
\hline Wingspan & 224 & 2 & 0 & 0.96 & 4 & 6.25 \\
\hline Enterprises & 443 & 1 & - & 3 & - & 2 \\
\hline Leo & 64 & 5 & 2 & - & 14 & 0 \\
\hline Solitaire & 96 & 0 & 0 & 0 & - & 6 \\
\hline Silk & 438 & 3 & $>1$ & 10 & 7 & 3 \\
\hline PED & 444 & 2 & - & 7 & 3 & 4 \\
\hline Willis & 53 & 1.9 & - & 11.3 & 1.9 & 1.9 \\
\hline
\end{tabular}


References:

[1] [online], W.H.O. Cerebrovascular Disease. http://www.who.int/topics/cerebrovascular_accident/en/. (Accessed January 10, 2013)

[2] New Meditech, I.o. IntraCranial Stents Market - Technology \& Market Forecast report. http://www.prweb.com/releases/2010/06/prweb4197474.htm. (Access January 10, 2013)

[3] Arkuszewski, M.; Targosz-Gajniak, M.; Swiat, M.; Baron, J.; Zbroszczyk, M.; Jaworski, M.; Pieta, M.; Gruszczynska, K.; Opala, G. Acute Intracranial In-Stent Thrombosis After Angioplasty of Middle Cerebral Artery Symptomatic Stenosis: A Case Report. In Neurologist: United States, 2012; 18, pp 290-295.

[4] Lylyk, P.; Ferrario, A.; Pasbon, B.; Miranda, C.; Doroszuk, G., Buenos Aires experience with the Neuroform self-expanding stent for the treatment of intracranial aneurysms. $J$ Neurosurg, 2005, 102, (2), 235-241.

[5] Lessne, M.L.; Shah, P.; Alexander, M.J.; Barnhart, H.X.; Powers, C.J.; Golshani, K.; Ferrell, A.; Enterline, D.; Zomorodi, A.; Smith, T.; Britz, G.W., Thromboembolic complications after Neuroform stent-assisted treatment of cerebral aneurysms: the Duke Cerebrovascular Center experience in 235 patients with 274 stents. Neurosurgery, 2011, 69, (2), 369-375.

[6] Ferrell, A.S.; Golshani, K.; Zomorodi, A.; Smith, T.P.; Britz, G.W. Improved delivery of the Neuroform 3 stent: technical note. In J Neurointerv Surg: England, 2012; 4, pp 287-290.

[7] Fiorella, D.; Derdeyn, C.P.; Lynn, M.J.; Barnwell, S.L.; Hoh, B.L.; Levy, E.I.; Harrigan, M.R.; Klucznik, R.P.; McDougall, C.G.; Pride, G.L., Jr.; Zaidat, O.O.; Lutsep, H.L.; Waters, M.F.; Hourihane, J.M.; Alexandrov, A.V.; Chiu, D.; Clark, J.M.; Johnson, M.D.; Torbey, M.T.; Rumboldt, Z.; Cloft, H.J.; Turan, T.N.; Lane, B.F.; Janis, L.S.; Chimowitz, M.I. Detailed Analysis of Periprocedural Strokes in Patients Undergoing Intracranial Stenting in Stenting and Aggressive Medical Management for Preventing Recurrent Stroke in Intracranial Stenosis (SAMMPRIS). In Stroke: United States, 2012; 43, pp 2682-2688.

[8] Siddiq, F.; Chaudhry, S.A.; Khatri, R.; Rodriguez, G.J.; Tummala, R.; Suri, M.F.; Qureshi, A.I., Rate of postprocedural stroke and death in SAMMPRIS trial-eligible patients treated with intracranial angioplasty and/or stent placement in practice. Neurosurgery, 2012, 71, (1), 68-73.

[9] Gandini, R.; Chiaravalloti, A.; Pampana, E.; Massari, F.; Morosetti, D.; Spano, S.; Loreni, G.; Simonetti, G., Intracranial atheromatous disease treatment with the Wingspan stent system: Evaluation of clinical, procedural outcome and restenosis rate in a single-center series of 21 consecutive patients with acute and mid-term results. Clin Neurol Neurosurg, 2012. 115(6): 741-7

[10] Huang, Q.H.; Zou, C.; Zhang, Y.W.; Zhao, R.; Nie, J.H.; Liu, J.M., Vascular Perforation by Enterprise Stent During Stent-Assisted Coil Embolization for Intracranial Aneurysm. Cardiovasc Intervent Radiol, 2012. 36(3): 857-9

[11] Heller, R.S.; Safain, M.; Malek, A.M. Enterprise stents resulting from undetected incomplete stent apposition. In J Neurointerv Surg: England, 2012; 4, p e38.

[12] Ulus, S.; Yakupoglu, A.; Kararslan, E.; Islak, C.; Siva, A.; Kocer, N., Reversible intracranial parenchymal changes in MRI after MCA aneurysm treatment with stent-assisted coiling technique; possible nickel allergy. Neuroradiology, 2012, 54, (8), 897-899.

[13] Lubicz, B.; François, O.; Levivier, M.; Brotchi, J.; Balériaux, D., Preliminary experience with the enterprise stent for endovascular treatment of complex intracranial aneurysms: potential advantages and limiting characteristics. Neurosurgery, 2008, 62, (5), 1063-1069; 1069-1070.

[14] Mocco, J.; Fargen, K.M.; Albuquerque, F.C.; Bendok, B.R.; Boulos, A.S.; Carpenter, J.S.; Fiorella, D.J.; Hoh, B.L.; Howington, J.U.; Liebman, K.M.; Natarajan, S.K.; Rai, A.T.; Rodriguez-Mercado, R.; Siddiqui, A.H.; Snyder, K.V.; Veznedaroglu, E.; Hopkins, L.N.; Levy, E.I., Delayed thrombosis or stenosis following enterprise-assisted stentcoiling: is it safe? Midterm results of the interstate collaboration of enterprise stent coiling. Neurosurgery, 2011, 69, (4), 908-913; 913-904. 
[15] Lv, X.; Li, Y.; Jiang, C.; Yang, X.; Wu, Z., Potential advantages and limitations of the Leo stent in endovascular treatment of complex cerebral aneurysms. Eur J Radiol, 2011, 79, (2), 317-322.

[16] Perez, M.A.; Miloslavski, E.; Fischer, S.; Bazner, H.; Henkes, H. Intracranial thrombectomy using the Solitaire stent: a historical vignette. In J Neurointerv Surg: England, 2012; 4, p e32.

[17] Saver, J.L.; Jahan, R.; Levy, E.I.; Jovin, T.G.; Baxter, B.; Nogueira, R.G.; Clark, W.; Budzik, R.; Zaidat, O.O., Solitaire flow restoration device versus the Merci Retriever in patients with acute ischaemic stroke (SWIFT): a randomised, parallel-group, non-inferiority trial. Lancet, 2012, 380, (9849), 1241-1249.

[18] Mordasini, P.; Brekenfeld, C.; Byrne, J.V.; Fischer, U.; Arnold, M.; Heldner, M.R.; Ludi, R.; Mattle, H.P.; Schroth, G.; Gralla, J. Technical Feasibility and Application of Mechanical Thrombectomy with the Solitaire FR Revascularization Device in Acute Basilar Artery Occlusion . In AJNR Am J Neuroradiol, 2012. 34(1): 159-63

[19] Bae, G.S.; Kwon, H.J.; Kang, C.W.; Choi, S.W.; Kim, S.H.; Koh, H.S., Mechanical thrombectomy using a solitaire stent in acute ischemic stroke; initial experience in 40 patients. J Cerebrovasc Endovasc Neurosurg, 2012, $14,(3), 164-169$.

[20] Maimon, S.; Gonen, L.; Nossek, E.; Strauss, I.; Levite, R.; Ram, Z., Treatment of intra-cranial aneurysms with the SILK flow diverter: 2 years' experience with 28 patients at a single center. Acta Neurochir (Wien), 2012, $154,(6), 979-987$.

[21] Berge, J.; Biondi, A.; Machi, P.; Brunel, H.; Pierot, L.; Gabrillargues, J.; Kadziolka, K.; Barreau, X.; Dousset, V.; Bonafe, A., Flow-diverter silk stent for the treatment of intracranial aneurysms: 1-year follow-up in a multicenter study. AJNR Am J Neuroradiol, 2012, 33, (6), 1150-1155.

[22] Briganti, F.; Napoli, M.; Tortora, F.; Solari, D.; Bergui, M.; Boccardi, E.; Cagliari, E.; Castellan, L.; Causin, F.; Ciceri, E.; Cirillo, L.; De Blasi, R.; Delehaye, L.; Di Paola, F.; Fontana, A.; Gasparotti, R.; Guidetti, G.; Divenuto, I.; Iannucci, G.; Isalberti, M.; Leonardi, M.; Lupo, F.; Mangiafico, S.; Manto, A.; Menozzi, R.; Muto, M.; Nuzzi, N.P.; Papa, R.; Petralia, B.; Piano, M.; Resta, M.; Padolecchia, R.; Saletti, A.; Sirabella, G.; Bolgè, L.P., Italian multicenter experience with flow-diverter devices for intracranial unruptured aneurysm treatment with periprocedural complications--a retrospective data analysis. Neuroradiology, 2012, 54, (10), 1145-1152.

[23] Shobayashi, Y.; Tateshima, S.; Kakizaki, R.; Sudo, R.; Tanishita, K.; Vinuela, F. Intra-aneurysmal hemodynamic alterations by a self-expandable intracranial stent and flow diversion stent: high intra-aneurysmal pressure remains regardless of flow velocity reduction. In J Neurointerv Surg, 2012. Epub 2012 Oct 9

[24] de Barros Faria, M.; Castro, R.N.; Lundquist, J.; Scrivano, E.; Ceratto, R.; Ferrario, A.; Lylyk, P., The role of the pipeline embolization device for the treatment of dissecting intracranial aneurysms. AJNR Am J Neuroradiol, 2011, 32, (11), 2192-2195.

[25] McAuliffe, W.; Wenderoth, J.D., Immediate and midterm results following treatment of recently ruptured intracranial aneurysms with the Pipeline embolization device. AJNR Am J Neuroradiol, 2012, 33, (3), 487-493.

[26] McAuliffe, W.; Wycoco, V.; Rice, H.; Phatouros, C.; Singh, T.J.; Wenderoth, J., Immediate and midterm results following treatment of unruptured intracranial aneurysms with the pipeline embolization device. $A J N R A m \mathrm{~J}$ Neuroradiol, 2012, 33, (1), 164-170.

[27] Lai, X.B.; Li, M.H.; Tan, H.Q.; Luo, B.Y.; Zhu, Y.Q.; Wang, J.; Li, Y.D., Predictors of in-stent stenosis and occlusion after endovascular treatment of intracranial vascular disease with the Willis covered stent. $J$ Clin Neurosci, 2013, 20, (1), 122-127.

[28] De Bock, S.; Iannaccone, F.; De Santis, G.; De Beule, M.; Mortier, P.; Verhegghe, B.; Segers, P. Our capricious vessels: The influence of stent design and vessel geometry on the mechanics of intracranial aneurysm stent deployment. In J Biomech; 2012 Elsevier Ltd: United States, 2012; 45, pp 1353-1359.

[29] Tan, A.; Alavijeh, M.S.; Seifalian, A.M., Next generation stent coatings: convergence of biotechnology and nanotechnology. Trends Biotechnol, 2012, 30, (8), 406-409. 
[30] Chan, J.M.; Rhee, J.W.; Drum, C.L.; Bronson, R.T.; Golomb, G.; Langer, R.; Farokhzad, O.C., In vivo prevention of arterial restenosis with paclitaxel-encapsulated targeted lipid-polymeric nanoparticles. Proc Natl Acad Sci U S A, 2011, 108, (48), 19347-19352.

[31] Tan, A.; Farhatnia, Y.; de Mel, A.; Rajadas, J.; Alavijeh, M.S.; Seifalian, A.M., Inception to actualization: next generation coronary stent coatings incorporating nanotechnology. J Biotechnol, 2013, 164, (1), 151-170.

[32] Kabir, A.M.; Selvarajah, A.; Seifalian, A.M., How safe and how good are drug-eluting stents? Future Cardiol, 2011, 7, (2), 251-270.

[33] Farhatnia, Y.; Tan, A.; Motiwala, A.; Cousins, B.G.; Seifalian, A.M., Evolution of covered stents in the contemporary era: clinical application, materials and manufacturing strategies using nanotechnology. Biotechnol $A d v$, 2013, 31, (5), 524-542.

[34] Goh, D.; Tan, A.; Farhatnia, Y.; Rajadas, J.; Alavijeh, M.S.; Seifalian, A.M., Nanotechnology-based geneeluting stents. Mol Pharm, 2013, 10, (4), 1279-1298.

[35] Naghavi, N.; de Mel, A.; Alavijeh, O.S.; Cousins, B.G.; Seifalian, A.M., Nitric oxide donors for cardiovascular implant applications. Small, 2013, 9, (1), 22-35.

[36] Kealey, C.P.; Chun, Y.J.; Viñuela, F.E.; Mohanchandra, K.P.; Carman, G.P.; Viñuela, F.; Levi, D.S., In vitro and in vivo testing of a novel, hyperelastic thin film nitinol flow diversion stent. $J$ Biomed Mater Res $B$ Appl Biomater, 2012, 100, (3), 718-725.

[37] Ito, K.; Yonaha, H.; Kai, Y.; Hokama, Y.; Nagamine, H.; Miyagi, T.; Watanabe, T.; Ishiuchi, S. In Neurol Med Chir (Tokyo): Japan, 2012; 52, pp 902-905.

[38] Kim, D.H.; Rozhkova, E.A.; Ulasov, I.V.; Bader, S.D.; Rajh, T.; Lesniak, M.S.; Novosad, V., Biofunctionalized magnetic-vortex microdiscs for targeted cancer-cell destruction. Nat Mater, 2010. 9(2):165-71

[39] Nakazawa, G.; Granada, J.F.; Alviar, C.L.; Tellez, A.; Kaluza, G.L.; Guilhermier, M.Y.; Parker, S.; Rowland, S.M.; Kolodgie, F.D.; Leon, M.B.; Virmani, R., Anti-CD34 antibodies immobilized on the surface of sirolimus-eluting stents enhance stent endothelialization. JACC CardiovasC Interv, 2010, 3, (1), 68-75.

[40] Motwani, M.S.; Rafiei, Y.; Tzifa, A.; Seifalian, A.M., In situ endothelialization of intravascular stents from progenitor stem cells coated with nanocomposite and functionalized biomolecules. Biotechnol Appl Biochem, 2011, $58,(1), 2-13$.

[41] de Mel, A.; Jell, G.; Stevens, M.M.; Seifalian, A.M., Biofunctionalization of biomaterials for accelerated in situ endothelialization: a review. Biomacromolecules, 2008, 9, (11), 2969-2979.

[42] Kidane, A.G.; Burriesci, G.; Edirisinghe, M.; Ghanbari, H.; Bonhoeffer, P.; Seifalian, A.M., A novel nanocomposite polymer for development of synthetic heart valve leaflets. Acta Biomater, 2009, 5, (7), $2409-2417$.

[43] Kannan, R.Y.; Salacinski, H.J.; De Groot, J.; Clatworthy, I.; Bozec, L.; Horton, M.; Butler, P.E.; Seifalian, A.M., The antithrombogenic potential of a polyhedral oligomeric silsesquioxane (POSS) nanocomposite.

Biomacromolecules, 2006, 7, (1), 215-223.

[44] Kannan, R.Y.; Salacinski, H.J.; Ghanavi, J.E.; Narula, A.; Odlyha, M.; Peirovi, H.; Butler, P.E.; Seifalian, A.M., Silsesquioxane nanocomposites as tissue implants. Plast Reconstr Surg, 2007, 119, (6), 1653-1662.

[45] Kannan, R.Y.; Salacinski, H.J.; Sales, K.M.; Butler, P.E.; Seifalian, A.M., The endothelialization of polyhedral oligomeric silsesquioxane nanocomposites: an in vitro study. Cell Biochem Biophys, 2006, 45, (2), 129-136.

[46] Punshon, G.; Vara, D.S.; Sales, K.M.; Kidane, A.G.; Salacinski, H.J.; Seifalian, A.M., Interactions between endothelial cells and a poly(carbonate-silsesquioxane-bridge-urea)urethane. Biomaterials, 2005, 26, (32), 62716279.

[47] Fu, B.X.; Gelfer, M.Y.; Hsiao, B.S.; Phillips, S.; Viers, B.; Blanski, R.; Ruth, P., Physical gelation in ethylenepropylene copolymer melts induced by polyhedral oligomeric silsesquioxane (POSS) molecules. Polymer, 2003, 44, (5), 1499-1506. 
[48] Haddad, T.S.; Lichtenhan, J.D., Hybrid organic-inorganic thermoplastics: Styryl-based polyhedral oligomeric silsesquioxane polymers. Macromolecules, 1996, 29, (22), 7302-7304.

[49] Oaten, M.; Choudhury, N.R., Silsesquioxane-urethane hybrid for thin film applications. Macromolecules, 2005, 38, (15), 6392-6401.

[50] Rashid, S.T.; Fuller, B.; Hamilton, G.; Seifalian, A.M., Tissue engineering of a hybrid bypass graft for coronary and lower limb bypass surgery. FASEB J, 2008, 22, (6), 2084-2089.

[51] Chaloupka, K.; Motwani, M.; Seifalian, A.M., Development of a new lacrimal drainage conduit using POSS nanocomposite. Biotechnol Appl Biochem, 2011, 58, (5), 363-370.

[52] Elliott, M.J.; De Coppi, P.; Speggiorin, S.; Roebuck, D.; Butler, C.R.; Samuel, E.; Crowley, C.; McLaren, C.; Fierens, A.; Vondrys, D.; Cochrane, L.; Jephson, C.; Janes, S.; Beaumont, N.J.; Cogan, T.; Bader, A.; Seifalian, A.M.; Hsuan, J.J.; Lowdell, M.W.; Birchall, M.A., Stem-cell-based, tissue engineered tracheal replacement in a child: a 2-year follow-up study. Lancet, 2012, 380, (9846), 994-1000.

[53] Jungebluth, P.; Alici, E.; Baiguera, S.; Le Blanc, K.; Blomberg, P.; Bozoky, B.; Crowley, C.; Einarsson, O.; Grinnemo, K.H.; Gudbjartsson, T.; Le Guyader, S.; Henriksson, G.; Hermanson, O.; Juto, J.E.; Leidner, B.; Lilja, T.; Liska, J.; Luedde, T.; Lundin, V.; Moll, G.; Nilsson, B.; Roderburg, C.; Stromblad, S.; Sutlu, T.; Teixeira, A.I.; Watz, E.; Seifalian, A.; Macchiarini, P., Tracheobronchial transplantation with a stem-cell-seeded bioartificial nanocomposite: a proof-of-concept study. Lancet, 2011, 378, (9808), 1997-2004. 